\title{
Salty Urbanism: Toward an Adaptive Coastal Design Framework to Address Rising Seas and Climate Change
}

\author{
JEFFREY E. HUBER, AIA, ASLA, NCARB, LEED AP \\ Florida Atlantic University
}

Keywords: Salty Urbanism, Resilient Redesign, Adaptation Design, Sea-level Rise, Climate Disruption

Over the next 100 years, nothing will radically change the coastal built environment more than climate change and sealevel rise. The coastal zone is home to some of our country's most valuable ecological and socio-economic assets. Many of these locations are being demonstrably transformed due to large-scale human and biophysical processes. The result is a potential loss of myriad ecosystem services such as storm protection, wildlife habitat, recreation and aesthetics, among others. Policy and design solutions are not truly considering the necessary transformation that will be required to live and work within a saturated coastal environment. The old paradigm of flood management and control will need to change from prevention to acceptance and population will decline as businesses and individuals decide the costs are too high. The need for developing a long-term urban design and planning framework that adapts to these effects is critical. More specifically, there is a need for a "systems" approach that utilizes urban design and takes into consideration infrastructure impacts, future investments, and insurability of risk as long-term objectives to address potential impacts from both coastal flooding and rising sea levels, while at the same time guiding communities' future land use and investment plans.

Considering the Brookings Institute's statistic that $\mathbf{5 0 \%}$ of the built environment projected to exist by 2050 currently does not exist, there is an enormous opportunity to create an innovative coastal-hazard adaptation design approach and urban place-building framework to protect economic, engineering, environmental, and quality of life issues from potential impacts of sea-level rise, storm surge, rainfall and runoff within coastal zones. Urban design thinking brings problems involving community-scaled systems related to energy, food production, water, waste, and transit. Only urban design gives the architectural and planning professions a holistic framework through which these systems can be engaged, even though urbanism is often the missing piece in discussions on resilience and smart growth planning.

Utilizing Fort Lauderdale, Florida, and Venice, California as case studies, Salty Urbanism establishes an interdisciplinary team to develop a coupled research methodology and pedagogical approach that envisions and quantifies the experiential and ecological outcomes of alternative ways forward for these cities in response to climate instability, disruption and rising sea levels. These outcomes consider an inevitable future of saturated landscapes and, as a result, integrate research models that accommodate a variety of low impact development (LID), flood-adaptive architectural design and other alternative concepts to be implemented over time. In order to change the prevailing land-development models to favor integration of ecosystem functioning in urban development, this project proposes a multi-scale approach within the embedded scales of the building, lot, public rights-of-way (streets, easements, parks, etc.), and neighborhood, to generate feedback between bottom-up design thinking and top-down policy and planning production. Best management practices alone may address issues of urban stormwater management; however, they will not lessen flood potential as environmental engineering and urban planning disciplines are practiced as separate fields. Salty Urbanism provides a new tool and design methodology that helps connect segregated disciplines to meet the complex challenges.

\section{DESIGN FOR THE ANTHROPOCENE}

Social scientists and ecologists both agree that new policies which reshape design thinking to transgress global threats of climate disruption by approaches or even overstepping current policies are required to avoid the inevitable risks to communities and the built environment. These threats are global, long-lasting, uncertain, and interconnected, therefore solutions must be hyper localized to minimize conflicts and take advantage of potential synergies. Establishment of policies and design frameworks that are effective at a local level requires strategic analyses of the underlying conditions and understanding of scientific, livability, engineering, and legal approaches, as well as take local politics into account.

\section{BRIDGING ECOSYSTEM AND URBAN SERVICES}

Just as these environmental pressures have synergistic causes, there exists a great potential for synergistic solutions. In the 1960s, Ian McHarg's Design with Nature provided a model for rethinking and bridging ecological and urban design. However policy still fell short, academics and urban designers have 


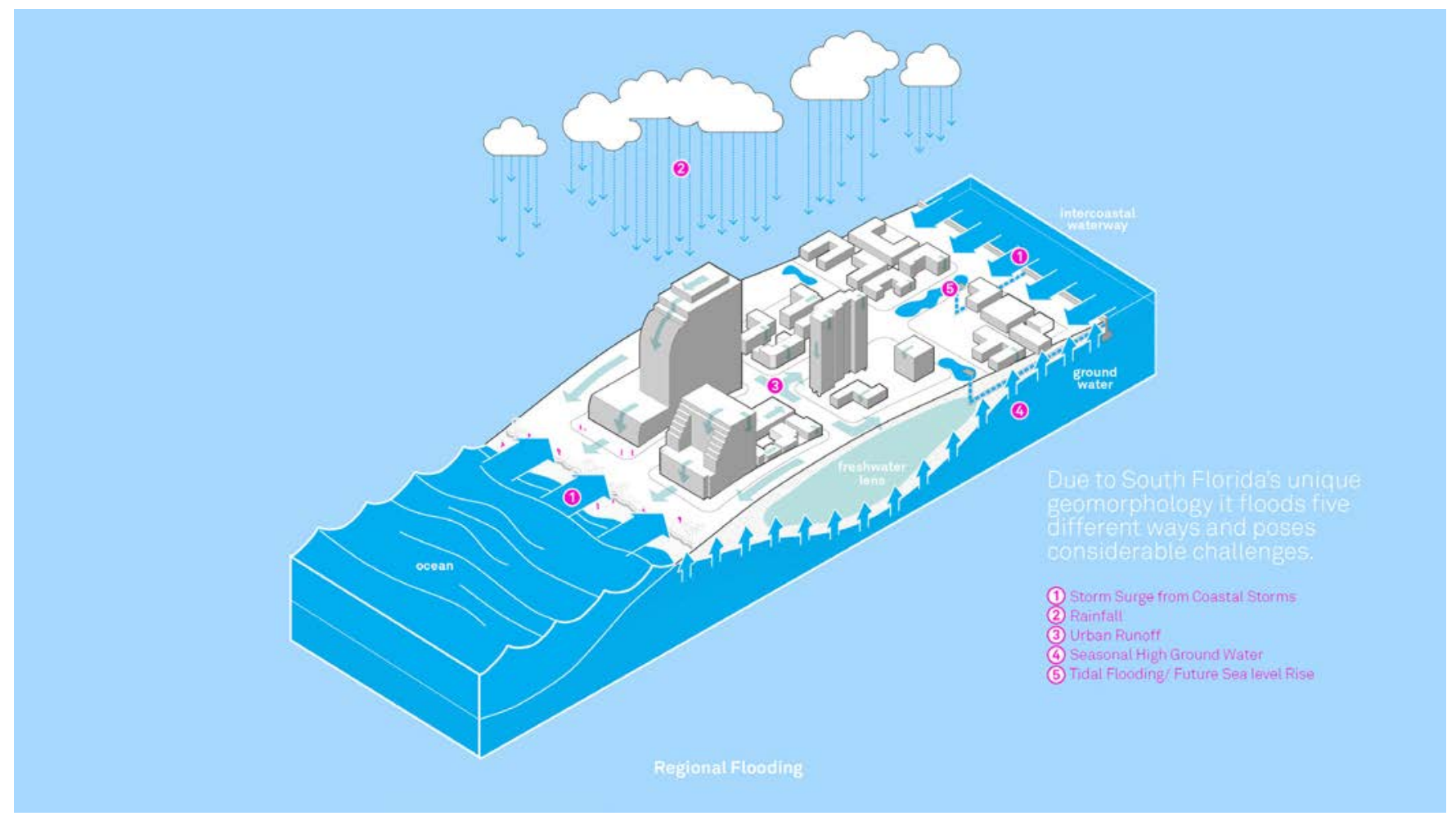

Figure 1. Five forms of regional flooding. Huber, Salty Urbanism.

given increasing attention again in recent years to "green infrastructure" and "nature-based features" as potential solutions to infrastructural problems normally relegated to purely engineering-based frameworks within the built environment. The reasoning for this revised perspective is largely due to the biological nature of the compounding environmental problems at hand. Functioning ecological systems produce a host of services essential to healthy societies, free of cost, and within a potentially indefinite scope of renewability. In south Florida, specifically, healthy coastal ecosystems (mangrove forests, seagrass beds, coral reefs, oyster reefs, etc.) provide a multitude of provisioning, regulating, and cultural ecosystem services, which not only support the economy (tourism, fisheries, aquaculture, etc.) but also the well-being and way of life for the millions of South Florida residents who live here yearround. The huge loss of these ecosystems along the southeast coast has had a resultant loss in ecosystem services, which has serious economic implications since tourism is a central source of income for industries in the area. Considering the benefits to water quality, storm protection, and urban livability, restoring the living components of shorelines in a urbanized setting stands to produce a host of synergistic benefits.

\section{SALTY URBANISM AS A FRAMEWORK FOR ADAPTATION DESIGN AND PLANNING IN THE COASTAL ZONE}

Coastal areas face a gamut of environmental threats that span across spatial and temporal scales and involve collaboration among many disciplines. Participants range from practicing architects and planners negotiating site, infrastructure and architectural issues, to researchers involved in modeling climate, sea-level rise and urban development patterns along coastal corridors. The complexity of environmental issues, as well as the diversity of disciplines and methodologies involved, present substantial barriers to establishing integrated solutions that might be possible within a more collaborative and comprehensive framework. Parallel to this, coupling ecosystem services with urban development is at obvious odds with current planning policies and zoning regulations. The situation summons creative approaches on how to retrofit architecture and planning to address paradigm-shifting threats of storm surge, sea-level rise, and fluctuating rainfall and runoff patterns. Defending against water encroachment from all directions is a particularly unique challenge of South Florida (Fig. 1), making it a good candidate for development of an adaptation framework that can be appropriated by coastal communities.

From an urban development/urban design perspective, the real challenge for developing resilient communities is ensuring ecosystem integrity within urban contexts since developers, nor municipal and county governments have mainstreamed green infrastructure within regulatory practices or design standards. Urban waterfronts have developed according to local social context-economics, recreation, and land use needs, which often denude coastal areas of native landscapes. 


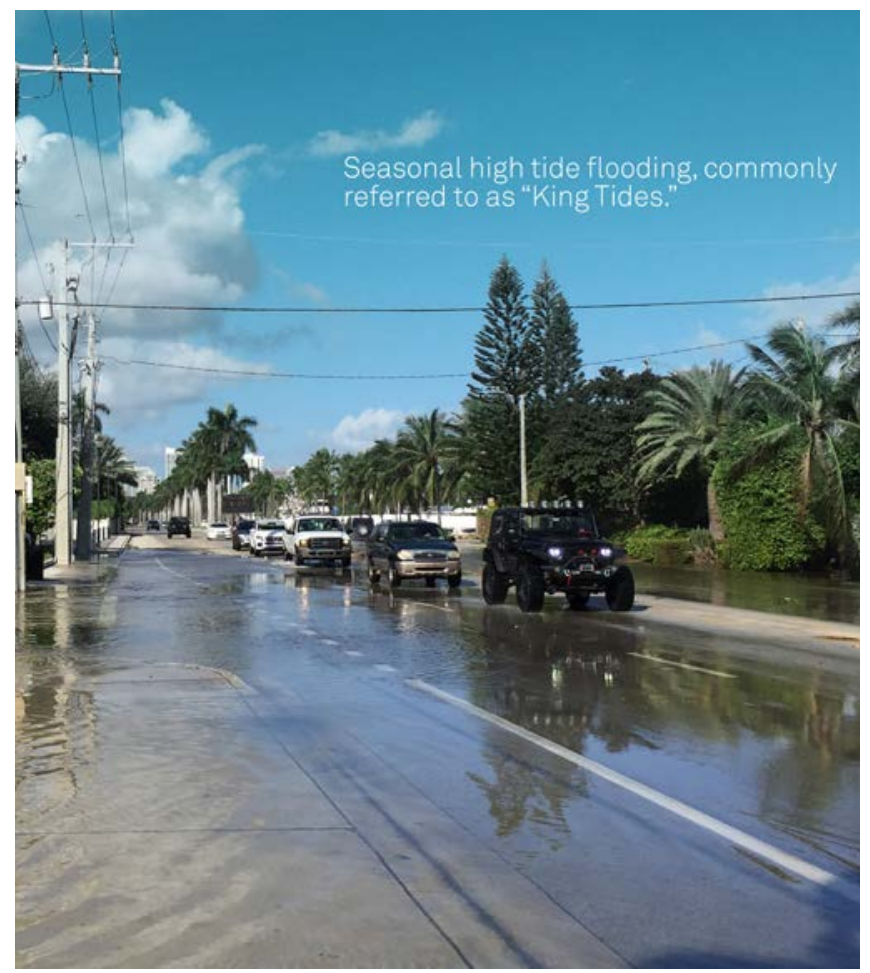

Figure 2. Image of King Tide flooding in Fort Lauderdale. Huber.

A much-needed place-building model that illustrates waterfront design standards while engaging socio-environmental development challenges will collectively yield a new ecology of the city necessary to address ecological design within humandominated ecosystems. Only urbanism-urban design and the allied fields that engage in it-gives the architectural and planning professions a holistic framework through which these systems can be engaged, even though urban design is usually the missing piece in discussions on adaptation and resiliency. More than the impacts from alternative energy sources and supply-side green technologies (photovoltaics, fuel cells, rain water harvesting, etc.), our land development/stewardship patterns are by far the most comprehensive venues for tackling climate change, energy conservation, and social equity. Municipalities and private development have yet to mainstream green infrastructure practices. The challenge is how to retrofit traditional planning and urban design to include addressing storm surge, sea-level rise, and changing rainfall and runoff patterns on the heavily-developed coastal zone.

Perhaps even more challenging is expanding Salty Urbanism to support new and creative urban development capable of solving the complex and multi-faceted issues of urban placemaking - approaches to the design, planning, and management of public space, while planning for likely retreat and urban decommissioning (unplanning/rewilding) of parts of the existing shoreline. This framing will surely spark debate on the extent to which the governmental agencies must reconcile with the environment and quality of life concerns.
Best Management Practices (BMPs) alone may address issues of urban stormwater quality, however, they will not necessarily lessen flood potential, because the environmental engineering and urban planning disciplines-each with their own optimization practices-are often practiced as separate fields. The project's multi-scale approach (shoreline, lot, public rights-of-way, and neighborhood) provides a link between the large-scale policy-driven approach and bottom-up design thinking with scientific modeling to provide niche adaptation solutions. This is why the framework is structured around the concept of ecosystem services as sources of capital for producing resilient flood protection and urban place-building in coastal areas. The research addresses climate and environmental threats, while at the same time considering the social fabric of the neighborhood relative to economic, recreational and cultural factors. The research goes beyond simple stormwater management infrastructure engineering and design to create a unique comprehensive strategy that links isolated research into a meta-disciplinary framework-one that leverages engineering, ecology, social sciences, mapping, and urban design and planning to reward greater resilient planning while enhancing livability.

\section{DESIGN APPROACHES AND DEVELOPMENT OF A NEW MODEL FOR INTEGRATIVE THINKING}

Salty Urbanism develops an integrated research and pedagogical approach that envisions and quantifies the experiential and ecological outcomes of alternative development pathways in response to flooding events that are a result of rising sea levels (projected to be eight feet now by 2100 according to the Southeast Regional Climate Change Compact).

The framework scenarios consider an inevitable future of saturated landscapes and integrate research models that accommodate a variety of best management practices, green infrastructure tools (Fig. 3), and alternative urban design and architectural concepts to be implemented over time. An interscalar approach that fosters urban solutions at the scales of individual lots, public rights-of-way, and neighborhood proved an appropriate point of departure to manage the potentially awkward intersections of knowledge and to more effectively cross-reference the multiple interdependencies and challenges of urban and natural systems. The integration of design practice, speculative studio environments and interdisciplinary research was leveraged to develop a framework for designing adaptive coastal communities in the wake of rising sea levels, while at the same time preparing emerging professionals for the inevitable future challenges facing their disciplines.

Four design studios at three schools of architecture across the nation collaborated to envision future adaptation scenarios. Utilizing alternative planning scenarios, with results from asset modeling and a matrix of soft and hard engineering technologies, scenarios were explored through design visioning for North Beach Village, a small barrier-island neighborhood 


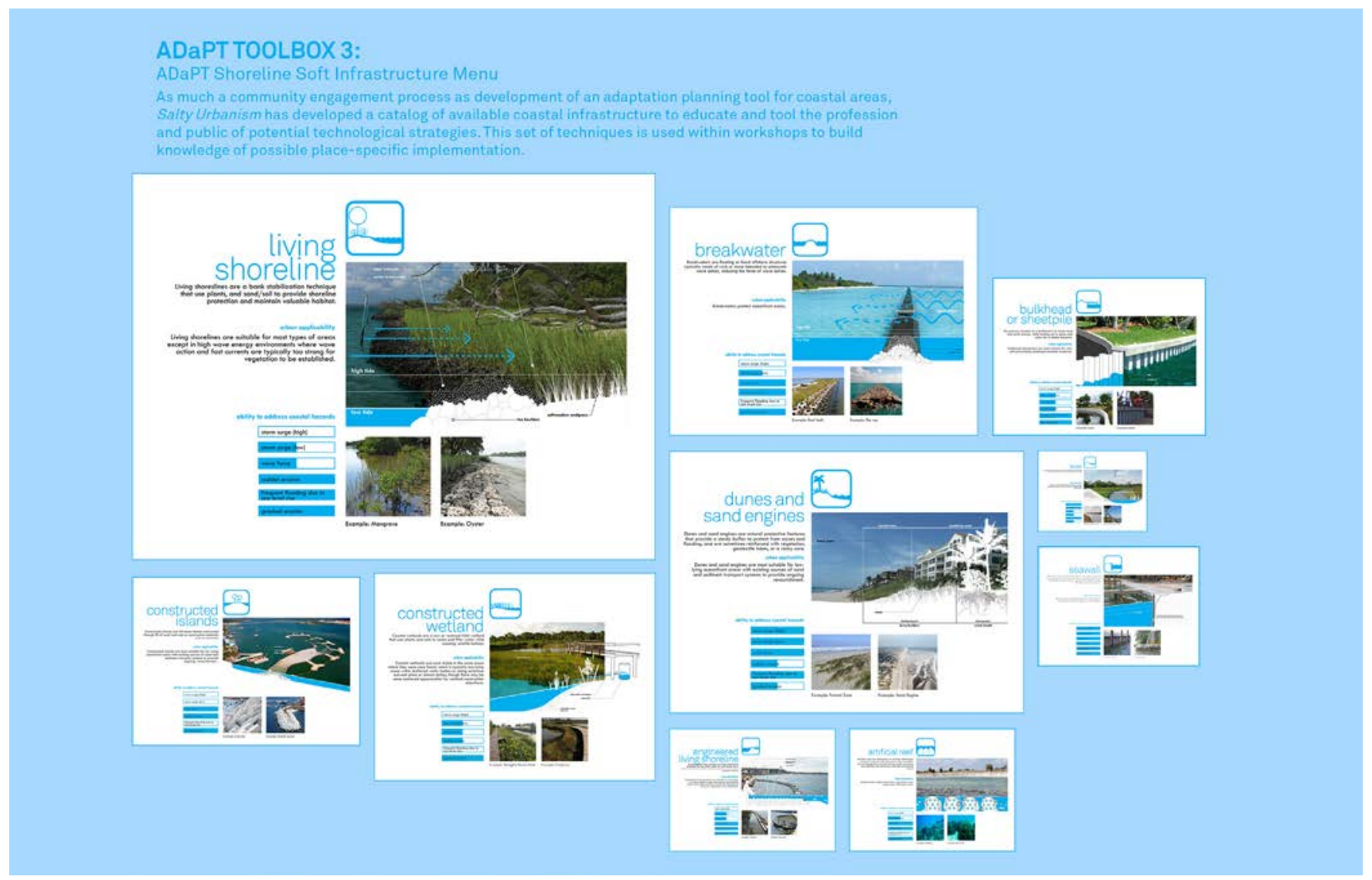

Figure 3. Shoreline Green Infrastructure Technologies. Huber, Salty Urbanism.

enclave in Fort Lauderdale. A robust set of strategies emerged that link ecological and urban design thinking. Similar to Fort Lauderdale the studios also applied the approach to Venice, California. The proposals re-think preconceptions about conventional infrastructure, since most students are unaware or have never designed for these complexities. Although some radical proposals were produced, they were plausibly comprehended by stakeholders - an indication of the severity of risk facing coastal areas, a threat increasingly recognized by experts and laypersons alike. The following is a general assessment and description of design outcomes within each scenario thinking.

Focusing on the North Beach Village scenario planning utilizing the Salty Urbanism design framework the four scenarios include a Business-as-Usual (if nothing was implemented and showing the projected permanent flooding by 2100) (Fig. 4), 1) Soft Defense, 2) Strategic Retreat, and 3) Land Adjust. The following explains the synthesized studio proposals.

"Soft Defense Scenario" (Fig. 5) combined strategies of both hard and soft engineering to mitigate impacts of rising seas and non-point source pollution from urban runoff allowing current development to remain largely unaltered. Installation of living shorelines, as well as bioswales and rain gardens in the street rights-of-way created high-tide gardens with salt-tolerant, halophytic landscapes and pervious paving systems. These saltwater landscapes become "biopumps" with phreatophytic vegetation-long-rooted trees that transpire significant amounts of water for hydraulic control, thereby reducing the time streets are flooded. Architectural strategies include allowing first floor levels to be designed to flood - a strategy already finding its way into building codes and architectural typologies in coastal areas.

"Strategic Retreat Scenario" (Fig. 6) accepts a lateral shift in urban footprint and develops a gradual removal of urban development through relocation to higher ground on the coastal ridge. Thus, a retreat enables naturalizing low-lying areas and intensifying urban development on higher ground through Transfer of Development Rights. This includes softengineered solutions that can be implemented over time as "rewilding" in both public and private properties. Through these scenarios, students participated in policy and regulation discussions as they pertain to the built environment and lifestyles of residents, thereby promoting awareness to the numerous politically sensitive issues that will factor in many adaptation strategies in coming decades. Policy and recommendations included a "Department of Unplanning" that can 


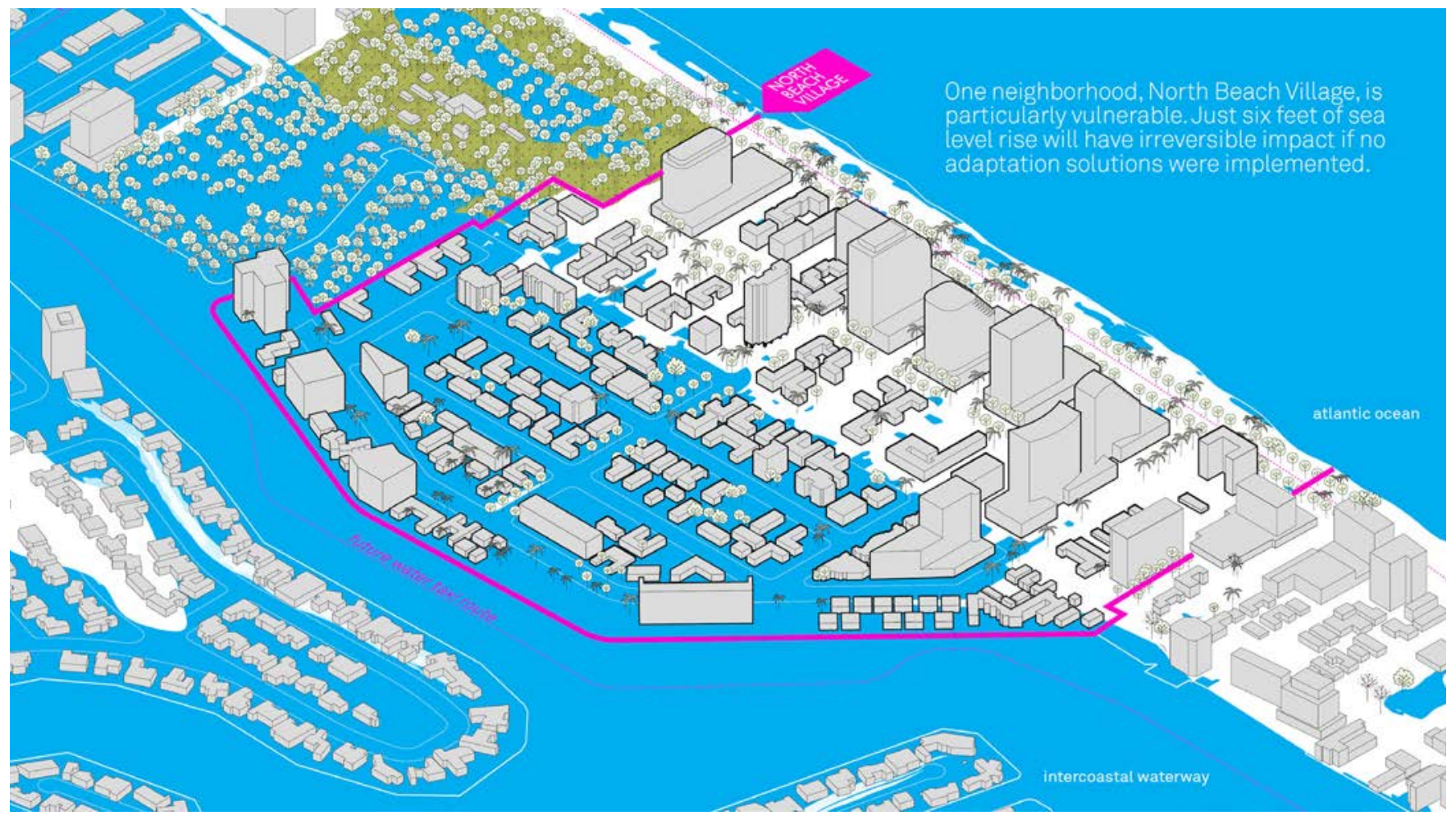

Figure 4.Business-as-Usual Scenario. Huber, Salty Urbanism.

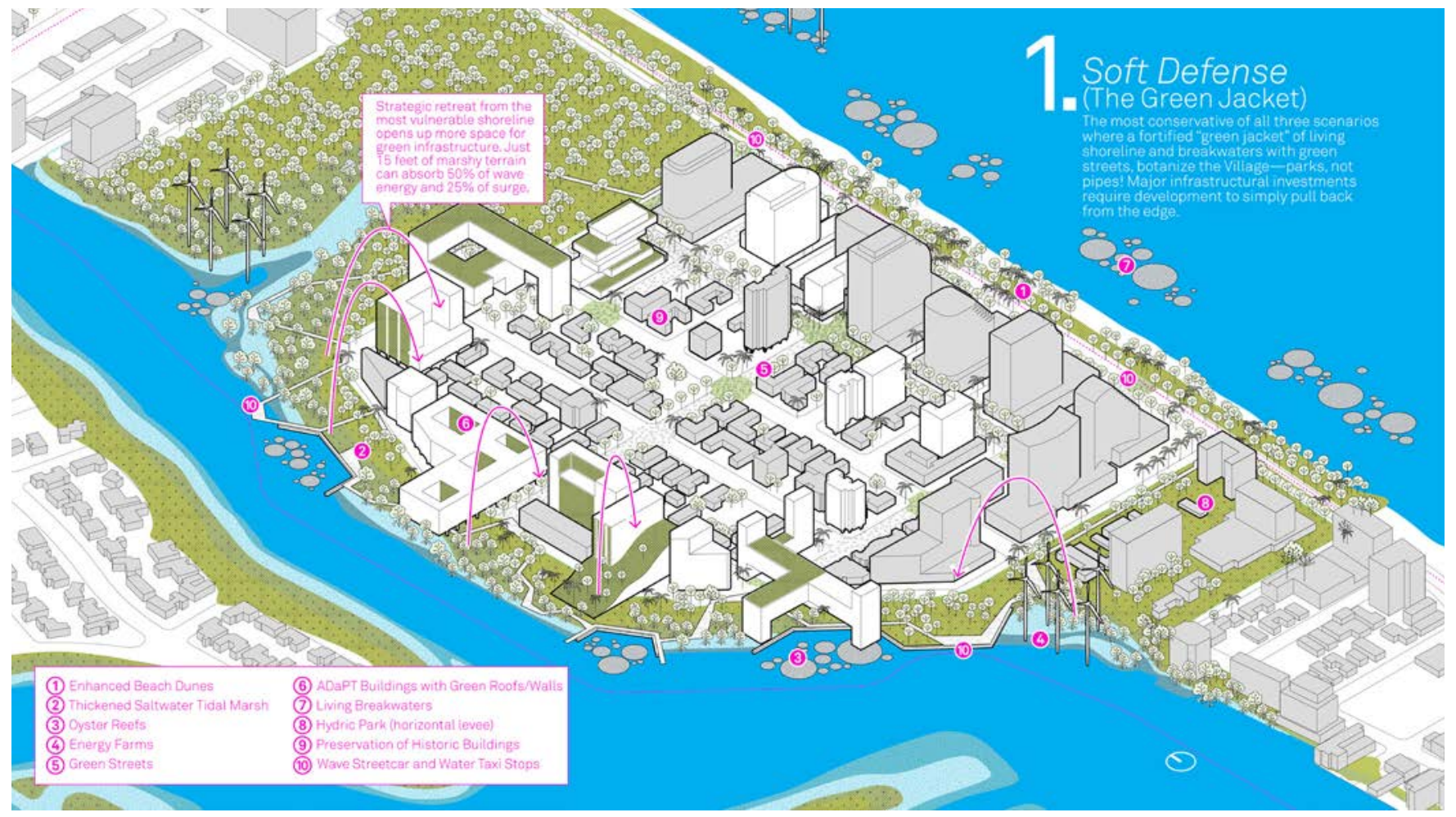




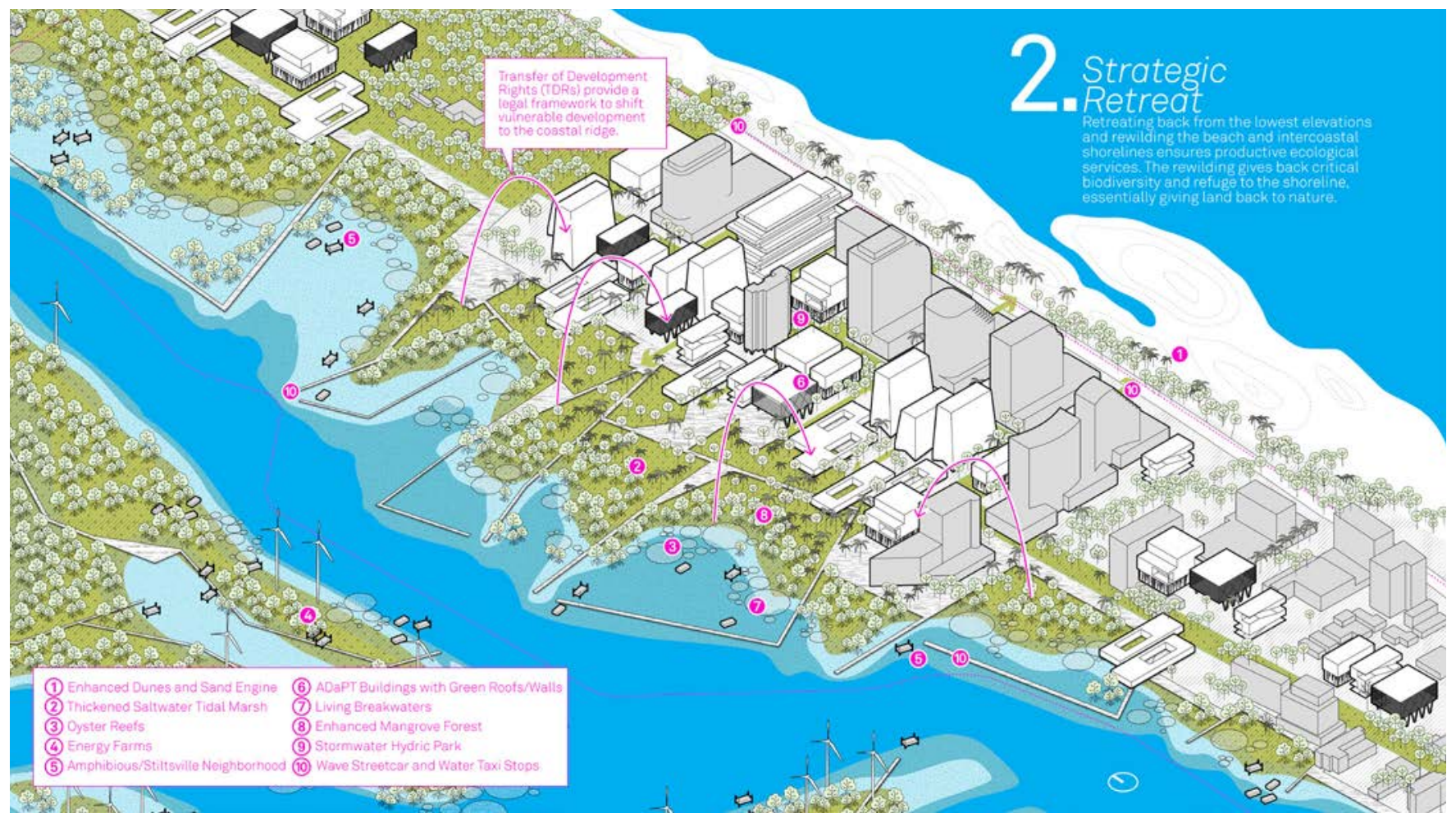

Figure 6. Strategic Retreat Scenario. Huber, Salty Urbanism.

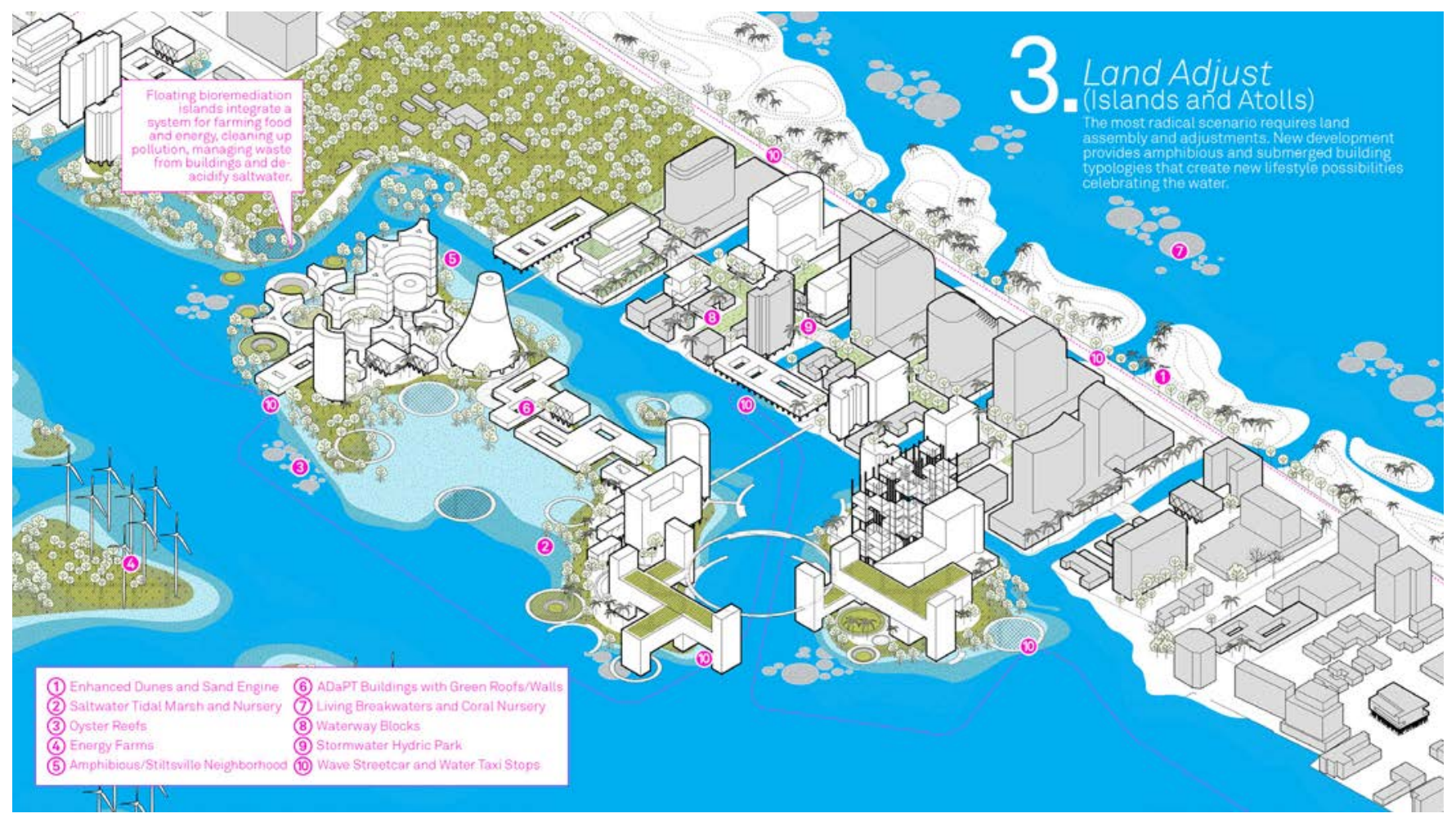


manage urban decommissioning. Additionally, amphibious and floating structures would be proposed within rewilded areas.

"Land Adjustment Scenario" (Fig. 7) reformats buildings, blocks, and streets into an idealized urban and ecological morphology approach. Unconventional building types that showcase raised platforms for habitation, floating structures, and submerged living units with a transition to more water-based transportation systems were explored. (Fig. 8) Micro-grid distributed power-generation plants and neighborhood-scaled utility systems would be implemented in order to create resilient and redundant infrastructure as neighborhoods become more disconnected from mainland services.

\section{CONCLUSION}

The development of integrated place-building models, like Salty Urbanism, engage socio-environmental development and collectively yield a new ecology of the city necessary to address the greatest ongoing challenge to planning and design: ecological design within human-dominated ecosystems. By adopting ecological terms, architecture and planning can achieve greater resilience and retool themselves with the ability to adapt to changing conditions. It is at this juncture that reconciliation ecology and urban design, provides a framework for innovation. Beyond composition, ecological thinking requires logics of assembly where timing, interactivity, sequencing, componentization, and recombination constitute another aesthetic and utilitarian intelligence. Urban design projects bring problems involving community-scaled systems that work in tandem to ecological and social resiliency. Salty Urbanism provokes a policy platform to change prevailing development codes which have diminished both urban and ecosystem services. Salty Urbanism forms a path toward permittable structures and infrastructure, albeit in a simplified form. Likewise, urban design and the architectural profession might serve as leaders to navigate substantial barriers and establish a more collaborative framework. Integration of research, practice and education-coupled with community partners and public interest design-may be the norm, rather than the exception, as urban areas face increased uncertainty resulting from environmental and social challenges.

Salty Urbanism repositions how we live, adapt and transition urban development, especially when we must leave or adapt to the land that is no longer high and dry. Therefore, just as governmental agencies have planning departments, so to, should they consider the establishment of a Department of Unplanning coupled with new bottom-up design frameworks and policies. Ultimately decisions will need to be made on which neighborhoods are abandoned and which will be modified and adapted beyond the scope of the presented scenarios. Furthermore, population decline will occur as businesses and individuals decide the costs are too high to maintain regional assets and decommissioning (unplanning) of the built environment will come into more clarity as a pressing challenge.

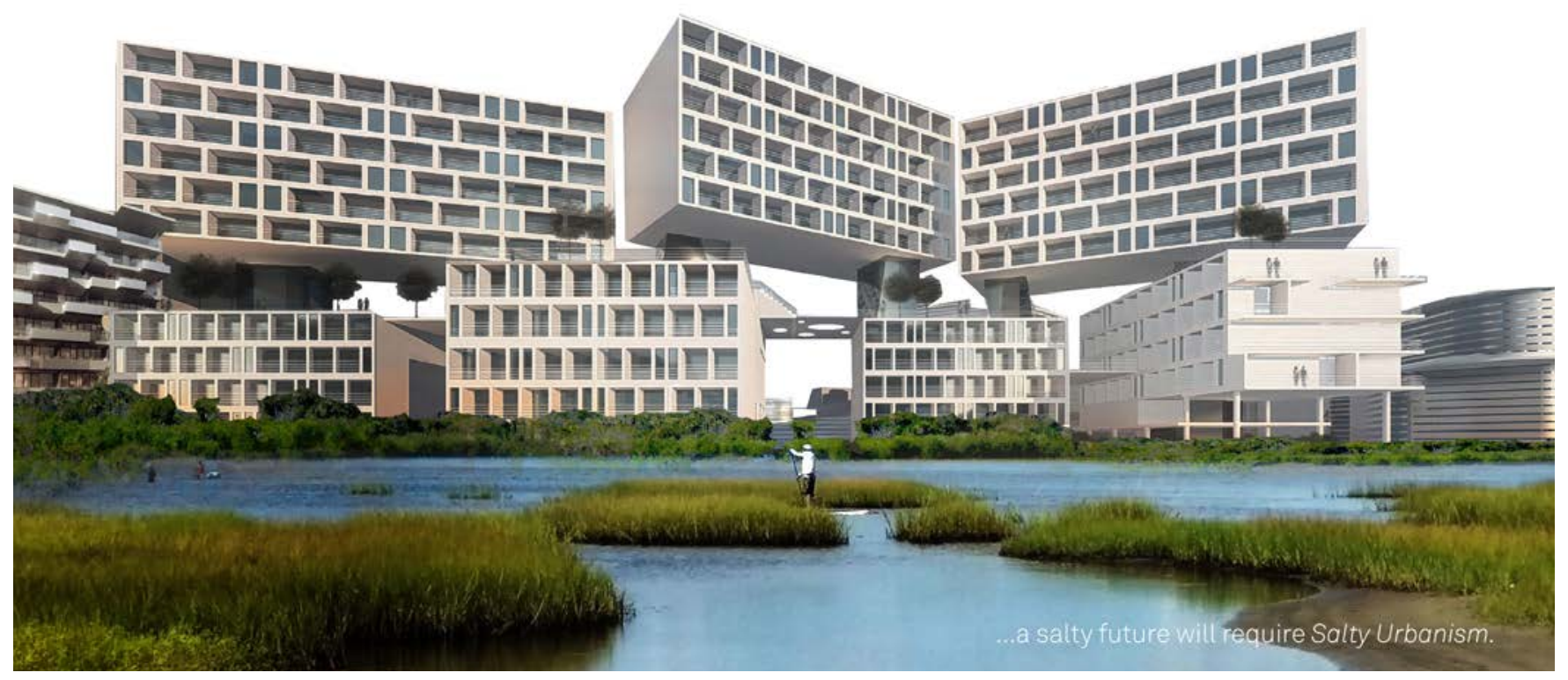

Figure 8. Rendered view of the Land Adjust Scenario. Huber, Salty Urbanism. 


\section{ENDNOTES}

$<$ ?>. $\quad$ Sterner, T., Barbier, E.B., Bateman, I. et al. Policy design for the Anthropocene. Nat Sustain 2, 14-21 (2019). https://doi.org/10.1038/ s41893-018-0194-x

<?>. $\quad$ Scyphers, S. B., T. C. Gouhier, J. H. Grabowski, M. W. Beck, J. Mareska, and S. P. Powers. 2015. Natural shorelines promote the stability of fish communities in an urbanized coastal system. PLoS One 10 (6):e0118580

<?>. Barbier, E. B. 2012. Progress and Challenges in Valuing Coastal and Marine Ecosystem Services. Review of Environmental Economics and Policy $6(1): 1-19$

<?>. Cook, G. S., P. J. Fletcher, and C. R. Kelble. 2013. Towards marine ecosystem based management in South Florida: quantifying interactions among ecosystem pressures, states, and services in a com plex coastal system. Ecological Indicators.

$<$ ?>. Rudolf Steven de Groot, "Environmental Functions and Economic Value of Ecosystems," in Investing in Natural Capital: The Ecologica Approach to Sustainability, eds. Ann Mari Jansson et al. (Washington DC: Island Press, 1994)

$<$ ? > $\quad$ Rosenzweig, Michael. Win-win Ecology, How the Earth's species can survive in the midst of human enterprise. (Oxford, UK: Oxford University Press, 2003)

$<$ ?>. Prough, Thomas and Costanza, Robert. Natural Capital and Human Survival (Solomons MD, USA: ISEE Press, 1995). 